\title{
STUDY OF SERUM URIC ACID LEVEL AS A RISK FACTOR AND FOR EVALUATING THE SEVERITY OF CORONARY ARTERY DISEASE
}

\author{
Shruthi $S^{1}$, Ramchandra Prabhu H. D2, Tirthankar Mukherjee ${ }^{3}$
}

${ }^{1}$ Assistant Professor, Department of General Medicine, Yenepoya Medical College University, Deralakatte, Mangalore.

${ }^{2}$ Associate Professor, Department of General Medicine, Kempegowda Institute of Medical Sciences and Research Centre, Bengaluru.

${ }^{3}$ Assistant Professor, Department of General Medicine, Kempegowda Institute of Medical Sciences and Research Centre, Bengaluru.

\section{ABSTRACT}

\section{BACKGROUND}

Few studies have assessed the relation of hyperuricemia with the severity of Coronary Artery Disease (CAD). This study investigated the association between high uric acid levels with the presence and severity of CAD.

\section{MATERIALS AND METHODS}

Fifty patients having angiographic evidence of atherosclerosis (CAD+case group) compared to 50 patients with no luminal stenosis $(n=)$ or with $<50 \%$ luminal stenosis $(n=)$ at coronary angiography (CAD-control group).

\section{RESULTS}

The mean age of the patients was $60 \pm 10$ years (317 men, 58.7\%). Hyperuricemia was more likely associated with a trend toward higher vessel scores indicating a more severe CAD (adjusted OR=1.51, 95\% $\mathrm{CI}=1.09-2.09 ; \mathrm{P}=0.005$ ) in the whole population.

\section{CONCLUSION}

Asymptomatic hyperuricemia was associated with the presence and severity of angiographically-defined CAD in patients with suspicious symptoms for CAD.

\section{KEYWORDS}

Uric Acid, CAD, Angiography.

HOW TO CITE THIS ARTICLE: Shruthi S, Prabhu RHD, Mukherjee T. Study of serum uric acid level as a risk factor and for evaluating the severity of coronary artery disease. J. Evolution Med. Dent. Sci. 2016;5(77):5678-5683, D0I: $10.14260 /$ jemds/2016/1281

\section{INTRODUCTION}

Coronary heart disease is a worldwide health epidemic. Although, age-specific events related to CHD have fallen dramatically in the last few decades. The overall prevalence has risen as population, age and patients survive the initial coronary or cardiovascular event. Worldwide, 30 percent of all deaths can be attributed to cardiovascular disease of which more than half are caused by CHD (coronary heart disease) and the forecasts for the future estimate a growing number as a consequence of lifestyle changes in developing countries.

Globally, of those dying from cardiovascular diseases, 80 percent are in developing countries and not in the western world. Global Burden of Disease (GBD) study reported that in 1990 there were 5.2 million deaths from cardiovascular diseases in economically developed countries and 9.1 million deaths from the same causes in developing countries. ${ }^{1}$

The prevalence of coronary artery disease in India has increased from 1 percent in 1960 to 9.7 percent in 1995 in urban populations and in rural populations it has almost doubled in the last decade. ${ }^{2}$ Coronary artery disease has a

Financial or Other, Competing Interest: None.

Submission 05-05-2016, Peer Review 02-07-2016,

Acceptance 07-07-2016, Published 23-09-2016.

Corresponding Author:

Dr. Shruthi $S$,

Flat No. 610, Meridian Apartments Near,

Gardenia Hostel Laxmigudda

Nithyananda Nagar Post,

Mangalore-575018.

E-mail: shuthibhat@gmail.com

DOI: $10.14260 /$ jemds/2016/1281 number of well-determined risk factors. The most common risk factors include smoking, family history, hypertension, obesity, diabetes, high alcohol consumption, lack of exercise, stress and hyperlipidaemia.

Hyperuricemia was postulated to be a risk factor for Coronary Artery Disease (CAD) more than 5 decades ago. Since then, numerous studies have investigated the association between elevated serum uric acid and CAD. Some studies found hyperuricemia to be an independent risk factor for CAD. We undertook this study to note the association between uric acid levels with the presence of CAD as an independent risk factor and to know relationships between uric acid levels and severity of CAD.

\section{AIM AND OBJECTIVES}

1. Study designed to determine the relationship of serum uric acid level with coronary artery disease.

2. To evaluate the risk factors of CAD including hyperuricemia to determine the independent predictors of CAD in male and female patients undergoing coronary angiography and

3. To explore whether there was a possible association between hyperuricemia and the severity of CAD in total and in men and women separately when adjusting for various confounding factors.

\section{METHODOLOGY}

The study of 100 cases with symptoms and risk factors of coronary artery disease patients undergoing coronary angiography at KIMS Hospital, Bengaluru, was conducted from September 2012 to May 2014. It was an observational prospective study for 18 months. 
All patients $>45$ years with risk factors of CAD, symptoms of CAD who were undergoing coronary angiography were included in the study.

Patients with Previous Percutaneous Transthoracic Coronary Angioplasty/stent implantation, Chronic heart failure, Gout symptoms, Chronic Alcoholic, Acute infectious and autoimmune disease, Chronic kidney disease, Neoplastic disease, Patients on Salicylates, diuretics ( $>2 \mathrm{gm})$, ethambutol, pyrazinamide were excluded from the study.

Patients having angiographic evidence of atherosclerosis ( $\geq 50$ percent luminal stenosis in at least 1 coronary artery or major branch segment in their epicardial coronary tree) were classified as having CAD (CAD+case group). Patients without luminal stenosis at coronary angiography were considered to have normal coronary and classified as not having CAD (CADcontrol group).

Coronary angiography was performed from the percutaneous femoral approach using standard angiographic techniques. The presence and severity of CAD was determined by vessel score. The angiograms were classified as revealing either no coronary lesions (absent), no coronary lesions with more than 50 percent luminal stenosis (minimal) or as having one (mild), two (moderate) or three (severe) major epicardial coronary arteries with more than 50 percent luminal obstructions. Left main stem (LMS) stenosis was regarded as one vessel. Patients with $<50$ percent luminal stenosis were classified as having minimal CAD. If the LMS and the Left Anterior Descending (LAD) and/or Left Circumflex (LCX) arteries were affected, this was counted as two points. The degree of stenosis was defined as the greatest percentage reduction of luminal diameter in any view compared with the nearest normal segment and was determined visually.

\section{Definitions of CAD Risk Factors}

Analysed risk factors of CAD included age, male gender, cigarette smoking, hyperlipidaemia, diabetes, hypertension, family history of CAD and hyperuricemia. Patients who currently smoked any kind of tobacco or who had quit smoking less than one month prior were considered current smokers. Hyperlipidaemia was defined as plasma total cholesterol level $\geq 200 \mathrm{mg} / \mathrm{dL}$, LDL-cholesterol level $\geq 130$ $\mathrm{mg} / \mathrm{dL}$, triglyceride level $\geq 200 \mathrm{mg} / \mathrm{dL}$ and HDL-cholesterol level $\leq 40 \mathrm{mg} / \mathrm{dL}$ or being on lipid lowering drugs at the time of the study. Patients were considered to have hypertension if arterial pressure was more than $140 / 90 \mathrm{mmHg}$ or were being treated with antihypertensive medications. Patients were considered to have diabetes if they were taking insulin or oral hypoglycaemic agents. Patients with lack of awareness of their past history of diabetes were defined as a fasting blood glucose $>126 \mathrm{mg} / \mathrm{dL}$. A positive family history was defined as CAD in a parent or sibling noted under the age of 55 for men and 65 for women. Patients with hyperuricemia were defined as serum uric acid concentrations $\geq 7.0 \mathrm{mg} / \mathrm{dL}$ in men and $\geq 6.0 \mathrm{mg} / \mathrm{dL}$ in women.

\section{DATA ANALYSIS}

The following Methods of Statistical Analysis have been used in this study.

1. The results for each parameter (numbers and percentages) for discrete data and averaged mean+standard deviation for continuous data are presented by student test.

2. The proportion was compared using chi-square test of significance.

In all the above tests, the $\mathrm{P}$ values were less than 0.05 , hence taken to be statistically significant. The data was analysed using Statistical Package for Social Science (SPSS, V 10.5).

\section{RESULTS}

Among these 100 patients, whom the inclusion and exclusion criteria were included in the study, 57 were males and 43 were females. 50 patients were included under CAD + group, 50 patients under CAD - group. In CAD + group, 29 were males and 21 females. In CAD - group, 28 males and 22 females. Mean age of patients was $60.1 \pm 9.387$ years.

Total 49 patients had hypertension out of which 29 $(50.9 \%)$ were male and $20(46.5 \%)$ were female. 59 patients had type 2 diabetes mellitus in which $35(61.4 \%)$ were male and 24 (55.8\%) females. Among 100 patients, 19 had family history of coronary artery disease with 12 (21.1\%) being males and 7 (16.3\%) being females. The men had a greater prevalence of hypertension, diabetes mellitus and hyperlipidaemia compared to women. Serum levels of creatinine and uric acid were significantly greater for men than women. Among 50 CAD patients, 7 had minimal, 9 had mild, 14 had moderate and 20 had severe coronary artery disease. Out of the above 50, 29 male patients had CAD with 5 (8.8\%), 5 (8.8\%), 9 (15.8\%) and 20 (17.5\%) having minimal, mild, moderate and severe CAD respectively and 21 female patients had CAD with 2 (4.7\%), 2 (9.3\%), 5 (11.6\%), 10 $(23.3 \%)$ having minimal, mild, moderate and severe CAD respectively.

\begin{tabular}{|c|c|c|c|c|}
\hline & Male $(\mathrm{N}=57)$ & Female $(\mathrm{N}=43)$ & Total $(\mathrm{N}=100)$ & 'p' value \\
\hline Age & $60.2 \pm 9.625$ & $60 \pm 9.174$ & $60.1 \pm 9.387$ & 0.924 \\
\hline Smoking & $37(64.9 \%)$ & $0(0.0 \%)$ & $37(37.0 \%)$ & $<0.001$ \\
\hline Diabetes & $35(61.4 \%)$ & $24(55.8 \%)$ & $59(59.0 \%)$ & 0.574 \\
\hline Hypertension & $29(50.9 \%)$ & $20(46.5 \%)$ & $49(49.0 \%)$ & 0.665 \\
\hline Family History of CAD & $12(21.1 \%)$ & $7(16.3 \%)$ & $19(19.0 \%)$ & 0.547 \\
\hline Severity of CAD & & & & \multirow{6}{*}{0.857} \\
\hline Absent & $28(49.1 \%)$ & $22(51.2 \%)$ & $50(50.0 \%)$ & \\
\hline Min. & $5(8.8 \%)$ & $2(4.7 \%)$ & $7(7.0 \%)$ & \\
\hline Mild & $5(8.8 \%)$ & $4(9.3 \%)$ & $9(9.0 \%)$ & \\
\hline Moderate & $9(15.8 \%)$ & $5(11.6 \%)$ & $14(14.0 \%)$ & \\
\hline Severe & $10(17.5 \%)$ & $10(23.3 \%)$ & $20(20.0 \%)$ & \\
\hline Hyperlipidaemia & $25(43.9 \%)$ & $21(48.8 \%)$ & $46(46.0 \%)$ & 0.621 \\
\hline Hyperuricemia & $29(50.9 \%)$ & $24(55.8 \%)$ & $53(53.0 \%)$ & 0.624 \\
\hline
\end{tabular}




\begin{tabular}{|c|c|c|c|c|}
\hline BMI & $24.1 \pm 1.9951$ & $24.8 \pm 2.6978$ & $24.4 \pm 2.3359$ & 0.145 \\
\hline Pulse & $83.44 \pm 12.493$ & $83.98 \pm 12.005$ & $83.67 \pm 12.227$ & 0.829 \\
\hline Systolic Blood pressure & $133.79 \pm 17.52$ & $127.63 \pm 10.395$ & $131.14 \pm 15.128$ & 0.043 \\
\hline Diastolic blood pressure & $79.58 \pm 9.333$ & $81.49 \pm 8.598$ & $80.4 \pm 9.03$ & 0.297 \\
\hline S. Creatinine & $1.03 \pm 0.277$ & $0.92 \pm 0.231$ & $0.98 \pm 0.263$ & 0.038 \\
\hline Uric acid (mg/dL) & $5.99 \pm 1.972$ & $5.5 \pm 1.744$ & $5.78 \pm 1.884$ & 0.203 \\
\hline $\begin{array}{c}\text { Fasting blood glucose } \\
\text { (mg/dL) }\end{array}$ & $116.35 \pm 58.018$ & $110.05 \pm 38.623$ & $113.64 \pm 50.465$ & 0.539 \\
\hline Triglyceride (mg/dL) & $177.35 \pm 55.153$ & $166.6 \pm 40.63$ & $172.73 \pm 49.493$ & 0.285 \\
\hline HDL-cholesterol (mg/dL) & $35.72 \pm 3.478$ & $36.14 \pm 3.299$ & $35.9 \pm 3.392$ & 0.542 \\
\hline LDL-cholesterol (mg/dL) & $119.37 \pm 32.429$ & $114.93 \pm 24.967$ & $117.46 \pm 29.397$ & 0.458 \\
\hline Total cholesterol (mg/dL) & $195.53 \pm 37.144$ & $193.79 \pm 33.517$ & $194.78 \pm 35.465$ & 0.810 \\
\hline \multicolumn{2}{|c|}{ Table I: The Baseline Characteristics of the Study Population } \\
\hline
\end{tabular}

Source: Compiled from primary data.

\begin{tabular}{|c|c|c|c|c|}
\hline & CAD - $(\mathrm{N}=50)$ & $\mathrm{CAD}+(\mathrm{N}=50)$ & Total $(\mathrm{N}=100)$ & 'p' value \\
\hline Age & $60.9 \pm 8.87$ & $59.3 \pm 9.902$ & $60.1 \pm 9.387$ & 0.397 \\
\hline \multicolumn{4}{|l|}{ Gender } & \multirow{3}{*}{0.840} \\
\hline Male & $28(56.0 \%)$ & $29(58.0 \%)$ & $57(57.0 \%)$ & \\
\hline Female & $22(44.0 \%)$ & $21(42.0 \%)$ & $43(43.0 \%)$ & \\
\hline Chest Pain & $38(76.0 \%)$ & $45(90.0 \%)$ & $83(83.0 \%)$ & 0.062 \\
\hline Breathlessness & $9(18.0 \%)$ & $14(28.0 \%)$ & $23(23.0 \%)$ & 0.235 \\
\hline Palpitations & $6(12.0 \%)$ & $3(6.0 \%)$ & $9(9.0 \%)$ & 0.295 \\
\hline Giddiness, Sweating & $0(0.0 \%)$ & $5(10.0 \%)$ & $5(5.0 \%)$ & 0.022 \\
\hline Smoking & $12(24.0 \%)$ & $25(50.0 \%)$ & $37(37.0 \%)$ & 0.007 \\
\hline Diabetes & $27(54.0 \%)$ & $32(64.0 \%)$ & $59(59.0 \%)$ & 0.309 \\
\hline Hypertension & $21(42.0 \%)$ & $28(56.0 \%)$ & $49(49.0 \%)$ & 0.161 \\
\hline Family history of CAD & $6(12.0 \%)$ & $13(26.0 \%)$ & $19(19.0 \%)$ & 0.074 \\
\hline Hyperlipidaemia & $5(10.0 \%)$ & $41(82.0 \%)$ & $46(46.0 \%$ & $<0.001$ \\
\hline Hyperuricemia & $3(6.0 \%)$ & $50(100.0 \%)$ & $53(53.0 \%)$ & $<0.001$ \\
\hline \multicolumn{4}{|l|}{ Severity of CAD } & \multirow{6}{*}{$<0.001$} \\
\hline Absent & $50(100.0 \%)$ & $0(0.0 \%)$ & $50(50.0 \%)$ & \\
\hline Min. & $0(0.0 \%)$ & $7(14.0 \%)$ & $7(7.0 \%)$ & \\
\hline Mild & $0(0.0 \%)$ & $9(18.0 \%)$ & $9(9.0 \%)$ & \\
\hline Moderate & $0(0.0 \%)$ & $14(28.0 \%)$ & $14(14.0 \%)$ & \\
\hline Severe & $0(0.0 \%)$ & $20(40.0 \%)$ & $20(20.0 \%)$ & \\
\hline BMI & $23.3 \pm 1.4463$ & $25.5 \pm 2.564$ & $24.4 \pm 2.3359$ & $<0.001$ \\
\hline Uric acid (mg/dL) & $4.094 \pm 0.993$ & $7.46 \pm 0.636$ & $5.777 \pm 1.884$ & $<0.001$ \\
\hline Fasting blood glucose (mg/dL) & $88.08 \pm 20.195$ & $139.2 \pm 58.347$ & $113.64 \pm 50.465$ & $<0.001$ \\
\hline Triglyceride $(\mathrm{mg} / \mathrm{dL})$ & $144.06 \pm 9.629$ & $201.4 \pm 56.381$ & $172.73 \pm 49.493$ & $<0.001$ \\
\hline HDL-cholesterol (mg/dL) & $35.58 \pm 2.749$ & $36.22 \pm 3.935$ & $35.9 \pm 3.392$ & 0.348 \\
\hline LDL-cholesterol (mg/dL) & $96.68 \pm 9.43$ & $138.24 \pm 27.854$ & $117.46 \pm 29.397$ & $<0.001$ \\
\hline Total cholesterol (mg/dL) & $184.8 \pm 31.558$ & $204.76 \pm 36.633$ & $194.78 \pm 35.465$ & 0.004 \\
\hline
\end{tabular}

Source: Compiled from primary data

According to the above Table II, hyperlipidaemia, hyperuricemia were seen in CAD+group, which was statistically significant $(<0.001)$. On coronary angiography, 50 percent had normal coronary arteries and 14 percent had minimal CAD. Mild, moderate, severe seen in 18, 28 and 40 percent of the patients, respectively. Mean levels of serum uric acid were significantly higher in CAD patients than in those without CAD in total. The baseline characteristics of the participants with and without CAD in total and in men and women individually are presented in Table IIIA and IIIB.

Mean levels of FBS, TG, LDL cholesterol level and total cholesterol level were more in $\mathrm{CAD}+$ group than CAD.

\begin{tabular}{|c|c|c|c|}
\hline & \multicolumn{2}{|c|}{ Male (N=57) } \\
\hline & CAD - (N=28) & CAD + (N=29) & 'p' value \\
\hline Age (Yrs.) & $60.6 \pm 9.708$ & $59.7 \pm 9.695$ & 0.733 \\
\hline Chest Pain & $20(71.4 \%)$ & $27(93.1 \%)$ & 0.031 \\
\hline Breathlessness & $6(21.4 \%)$ & $11(37.9 \%)$ & 0.173 \\
\hline Palpitations & $5(17.9 \%)$ & $2(6.9 \%)$ & 0.208 \\
\hline Giddiness, Sweating & $0(0.0 \%)$ & $3(10.3 \%)$ & 0.080 \\
\hline Smoking & $12(42.9 \%)$ & $25(86.2 \%)$ & 0.001 \\
\hline Diabetes & $16(57.1 \%)$ & $19(65.5 \%)$ & 0.516 \\
\hline
\end{tabular}




\begin{tabular}{|c|c|c|c|}
\hline Hypertension & $12(42.9 \%)$ & $17(58.6 \%)$ & 0.234 \\
\hline Family History of CAD & $5(17.9 \%)$ & $7(24.1 \%)$ & 0.561 \\
\hline Hyperlipidaemia & $1(3.6 \%)$ & $24(82.8 \%)$ & $<0.001$ \\
\hline Hyperuricemia & $0(0.0 \%)$ & $29(100.0 \%)$ & $<0.001$ \\
\hline BMI & $23.3 \pm 1.6069$ & $24.8 \pm 2.0577$ & 0.002 \\
\hline Uric acid (mg/dL) & $4.15 \pm 0.922$ & $7.76 \pm 0.579$ & $<0.001$ \\
\hline Fasting blood glucose (mg/dL) & $86.5 \pm 18.664$ & $145.2 \pm 68.153$ & $<0.001$ \\
\hline Triglyceride (mg/dL) & $144.18 \pm 9.246$ & $209.38 \pm 61.954$ & $<0.001$ \\
\hline HDL-cholesterol (mg/dL) & $35.04 \pm 2.925$ & $36.38 \pm 3.877$ & 0.146 \\
\hline LDL-cholesterol (mg/dL) & $95.36 \pm 4.931$ & $142.55 \pm 30.767$ & $<0.001$ \\
\hline Total Cholesterol (mg/dL) & $\mathbf{1 8 2 . 3 6 \pm 2 4}$ & $\mathbf{2 0 8 . 2 4 \pm 4 3 . 1 6 3}$ & $\mathbf{0 . 0 0 7}$ \\
\hline \multicolumn{2}{|r|}{ Table IIIA: Comparison of Risk Factors Among Male Patients With and Without CAD } \\
\hline
\end{tabular}

Source: Compiled from primary data

\begin{tabular}{|c|c|c|c|}
\hline & \multicolumn{3}{|c|}{ Female (N=43) } \\
\hline & CAD - (N=22) & CAD + (N=21) & 0.367 \\
\hline Age (yrs.) & $61.2 \pm 7.886$ & $58.7 \pm 10.389$ & 0.729 \\
\hline Chest Pain & $18(81.8 \%)$ & $18(85.7 \%)$ & 0.925 \\
\hline Breathlessness & $3(13.6 \%)$ & $1(14.3 \%)$ & 0.973 \\
\hline Palpitations & $1(4.5 \%)$ & $2(9.5 \%)$ & 0.138 \\
\hline Giddiness, Sweating & $0(0.0 \%)$ & $0(0.0 \%)$ & - \\
\hline Smoking & $0(0.0 \%)$ & $13(61.9 \%)$ & 0.432 \\
\hline Diabetes & $11(50.0 \%)$ & $11(52.4 \%)$ & 0.451 \\
\hline Hypertension & $9(40.9 \%)$ & $6(28.6 \%)$ & 0.033 \\
\hline Family history of CAD & $1(4.5 \%)$ & $17(81.0 \%)$ & $<0.001$ \\
\hline Hyperlipidaemia & $4(18.2 \%)$ & $21(100.0 \%)$ & $<0.001$ \\
\hline Hyperuricemia & $3(14.3 \%)$ & $26.3 \pm 2.9857$ & $<0.001$ \\
\hline BMI & $23.3 \pm 1.2492$ & $7.048 \pm 0.463$ & $<0.001$ \\
\hline Uric acid (mg/dL) & $4.023 \pm 1.094$ & $130.95 \pm 41.408$ & $<0.001$ \\
\hline Fasting blood glucose (mg/dL) & $90.09 \pm 22.275$ & $190.38 \pm 46.848$ & $<0.001$ \\
\hline Triglyceride (mg/dL) & $143.91 \pm 10.314$ & $36.0 \pm 4.099$ & 0.790 \\
\hline HDL-cholesterol (mg/dL) & $36.27 \pm 2.394$ & $132.29 \pm 22.614$ & $<0.001$ \\
\hline LDL-cholesterol (mg/dL) & $98.36 \pm 13.073$ & $199.95 \pm 25.254$ & 0.243 \\
\hline Total cholesterol (mg/dL) & $187.91 \pm 39.562$ & & \\
\hline Table IIB: Comparison of Risk Factors Among Female Patients With and Without CAD & \\
\hline
\end{tabular}

Source: Compiled from primary data.

In CAD+group, 93 percent of patients had chest pain, 28 percent breathlessness, 6 percent palpitations and 10 percent had associated other symptoms. Among male patients, 27 (93.1\%), 11 (37.9\%), 2 (6.9\%), $3(10.3 \%)$ had chest pain, breathlessness, palpitations and had associated with other symptoms, respectively. Among females in CAD+group, 18 (85.7\%), 3 (14.3\%), 1 (4.8\%), 2 (9.5\%) had above symptoms respectively. In CAD-group, $45(90 \%)$ patients had chest pain, $14(28 \%)$ had breathlessness, $3(6 \%)$ palpitation and $5(10 \%)$ other symptoms.

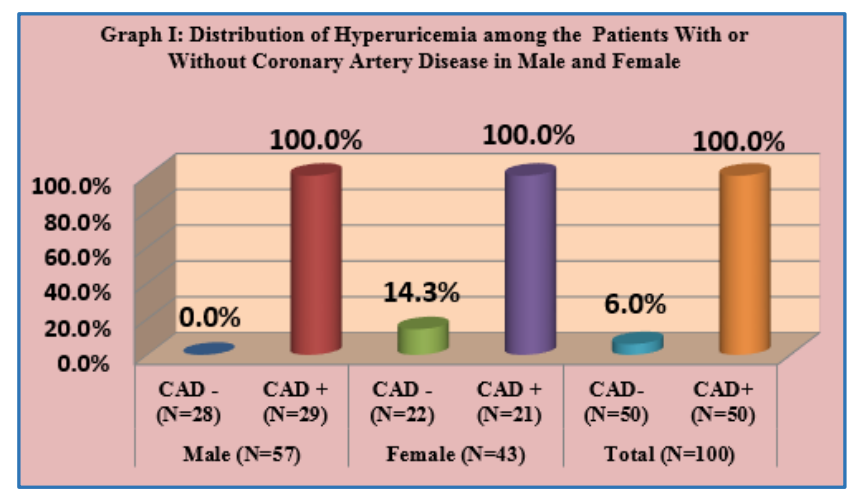

$50(100.0 \%)$ patients had hyperuricemia in CAD+group and $3(6.0 \%)$ in CAD-group. 29 (100\%) and $21(100.0 \%)$ were females in CAD+group.
Only $3(14.3 \%)$ in CAD-group had hyperuricemia who were all females, which was statistically significant as shown in the above Tables II, IIIA and B and Graph I, both males and females.

In CAD+group, mean uric acid level was $7.46 \pm 0.636 \mathrm{mg} \%$ with males having $7.76 \pm 0.579 \mathrm{mg} \%$ and females having $7.048 \pm 0.463 \mathrm{mg} \%$, which was statistically significant as shown in Table IIIA ( $\mathrm{p}$ value $<0.001$ ).

In CAD-group, mean uric acid level was $4.094 \pm 0.993 \mathrm{mg} \%$ with males having $4.15 \pm 0.922 \mathrm{mg} \%$ and Females having $4.023 \pm 1.094 \mathrm{mg} \%$ was statistically significant as shown in the Table IIIB ( $\mathrm{p}$ value $<0.001$ ).

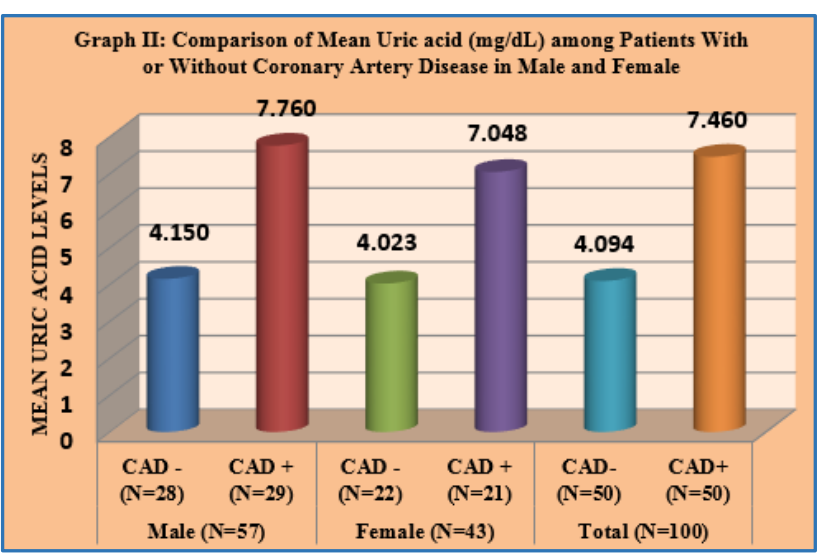




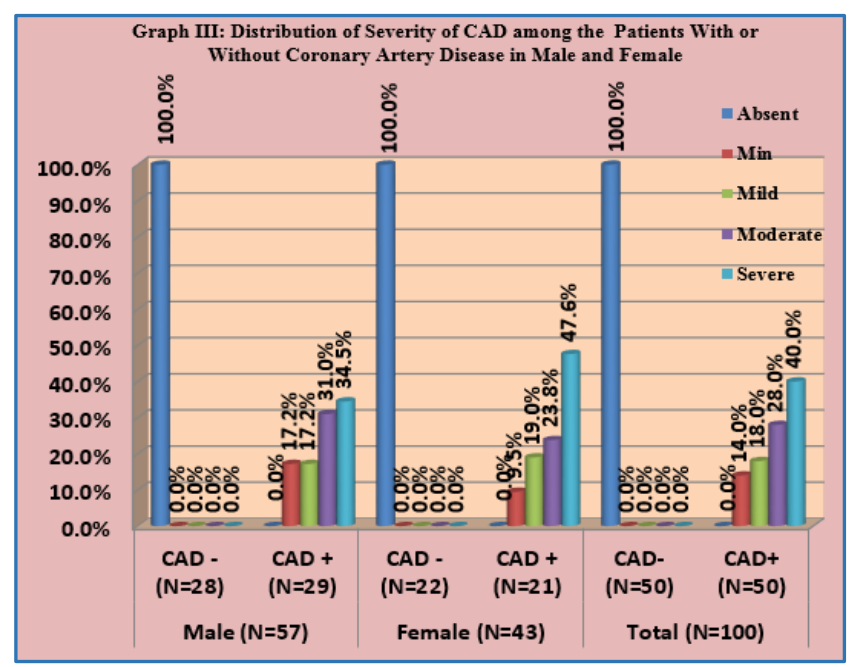

Among males in CAD positive group, 5 (17.2\%), 5 (17.2\%), 9 (31\%), 10 (34.5\%) had minimal, mild, moderate and severe CAD, which was statistically significant as shown in Table VI and Graph III.

Among females in CAD positive group, 2 (9.5\%), 4 (19\%), 5 (23.8\%), 10 (47.6\%) had minimal, mild, moderate and severe CAD, which was statistically significant as shown in Table VI above and Graph III.

\begin{tabular}{|c|c|c|c|c|c|c|}
\hline & Absent & Minimal & Mild & Moderate & Severe & 'p' value \\
\hline All & $\mathrm{n}=50$ & $\mathrm{n}=7$ & $\mathrm{n}=9$ & $\mathrm{n}=14$ & $\mathrm{n}=20$ & \\
\hline Uric acid (mg/dL) & $4.09 \pm 0.993$ & $7.09 \pm 0.219$ & $7.32 \pm 0.626$ & $7.40 \pm 0.485$ & $7.70 \pm 0.763$ & $<0.001$ \\
\hline Hyperuricemia & $3(6.0 \%)$ & $7(100.0 \%)$ & $9(100.0 \%)$ & $14(100.0 \%)$ & $20(100.0 \%)$ & $<0.001$ \\
\hline Male & $\mathrm{n}=28$ & $\mathrm{n}=5$ & $\mathrm{n}=5$ & $\mathrm{n}=9$ & $\mathrm{n}=10$ & \\
\hline Uric acid (mg/dL) & $4.15 \pm 0.922$ & $7.12 \pm 0.217$ & $7.60 \pm 0.235$ & $7.60 \pm 0.502$ & $8.30 \pm 0.427$ & $<0.001$ \\
\hline Hyperuricemia & $0(0.0 \%)$ & $5(100.0 \%)$ & $5(100.0 \%)$ & $9(100.0 \%)$ & $10(100.0 \%)$ & $<0.001$ \\
\hline Female & 22 & 2 & 4 & 5 & 10 & $<0.001$ \\
\hline Uric acid (mg/dL) & $4.02 \pm 1.094$ & $7.00 \pm 0.283$ & $6.98 \pm 0.826$ & $7.04 \pm 0.089$ & $7.09 \pm 0.482$ & $<0.001$ \\
\hline Hyperuricemia & $3(13.6 \%)$ & $2(100.0 \%)$ & $4(100.0 \%)$ & $5(100.0 \%)$ & $10(100.0 \%)$ & $<0.001$ \\
\hline
\end{tabular}

Source: Compiled from primary data.

Mean uric acid level in all patients according to severity of CAD was found to be $7.09 \pm 0.219 \mathrm{mg} \%$ in minimal, $7.32 \pm 0.626$ $\mathrm{mg} \%$ in mild, $7.40 \pm 0.485 \mathrm{mg} \%$ in moderate, $7.70 \pm 0.763 \mathrm{mg} \%$ in severe category respectively, which was statistically significant ( $\mathrm{p}$ value $<0.001$ ) as shown in the above Table VI.

Mean uric acid level in male patients according to severity of CAD was found to be $7.12 \pm 0.217 \mathrm{mg} \%, 7.60 \pm 0.235 \mathrm{mg} \%$, $7.60 \pm 0.502 \mathrm{mg} \%, \quad 8.30 \pm 0.427 \mathrm{mg} \%$ in minimal, mild, moderate, severe category of CAD, respectively. This is statistically significant as shown in above Table VI.

Mean uric acid level in female patients according to severity of CAD was found to be $7.00 \pm 0.283 \mathrm{mg} \%, 6.98 \pm 0.826$ $\mathrm{mg} \%, 7.04 \pm 0.089 \mathrm{mg} \%, 7.09 \pm 0.482 \mathrm{mg} \%$ in minimal, mild, moderate, severe form of CAD.

\section{DISCUSSION}

In our study of investigating 100 patients undergoing coronary angiography, we found that hyperuricemia was associated with the presence of angiographically documented CAD in the whole population in men and women individually, and that this association was independent of other confounding cardiovascular risk factors. Moreover, we found that patients with hyperuricemia showed independently a trend to more severe CAD scaled by vessel score.

Fang and colleagues in the NHANES I epidemiologic followup study on a representative sample of the United States adult population showed that increased levels of serum uric acid are related to increased cardiovascular morbidity and mortality. ${ }^{3}$ Madsen and colleagues suggested that in patients with significant CAD (stenosis $\geq 70 \%$ in coronary angiography), high levels of serum uric acid could be a strong risk factor for adverse outcome and mortality. ${ }^{4}$
Our findings add to the growing body of evidence that hyperuricemia is independently associated with the development of CAD. Despite this, because of complex interrelationships of uric acid levels with many other established cardiovascular risk factors such as metabolic syndrome, obesity, diabetes and chronic renal disease.5,6,7

In a Tuttle and colleagues study, there was also a linear correlation between uric acid levels and CAD severity in women, but not in men. ${ }^{8}$ Recently, Jelic-Ivanovic and colleagues compared the levels of uric acid in 356 patients with significant coronary lesion $(\geq 50 \%)$ as a case group with 350 people in a control group (coronary luminal narrowing $<50 \%$ ). After adjusting for confounders, they found differences between the uric acid concentrations in the case vs. control group only in women; no significant differences were observed in men with or without significant coronary lesions in their study. ${ }^{9}$

Persky et al studied, the association between uric acid and the prevalence of ECG abnormalities and with mortality appear to be secondary to associations between uric acid and other risk factors in men. ${ }^{10}$ Gur M, Yilmaz R, Demirbag R et al studied relation of serum uric acid levels with the presence of angiographic coronary artery disease. ${ }^{11}$ Some studies have found association of serum uric acid with ischaemic heart disease and hypertension. ${ }^{12}$

Li Qin†, Zhen Yang †, Hongxia Gu, Shuai Luet et al studied association between serum uric acid levels and cardiovascular disease in middle-aged and elderly Chinese individuals and concluded that elevated serum uric acid level was associated with cardiovascular disease, independent of conventional cardiovascular disease risk factors and metabolic syndrome. 13 
In our study, the independent adjusted association of hyperuricemia with the severity of CAD was investigated in patients having normal coronary arteries, minimal CAD, 1vessel, 2-vessel and 3-vessel disease. In our study, patients with smoking history, elevated BMI, hyperlipidaemia with elevated triglyceride, LDL, total cholesterol, elevated fasting blood sugar levels, hyperuricemia was associated with CAD + group.

\section{CONCLUSION}

Our total hyperuricemia study population was independently associated with angiographically documented CAD. Additionally, in multiple regressions, CAD severity in all and in men and women was independently related to hyperuricemia. Our findings suggest that asymptomatic hyperuricemia has an independent role in cardiovascular disease. Asymptomatic hyperuricemia was associated with the presence and severity of angiographically-defined CAD in patients with suspicious symptoms for CAD.

\section{REFERENCES}

1. Murray CJL, Lopez AD. Mortality by cause for eight regions of the world: global burden of disease study. Lancet 1997;349(9061):1269-76.

2. Gupta R, Gupta VP. Meta-analysis of coronary heart disease prevalence in India. Indian Heart J 1996;48(3):241-5.

3. Madsen TE, Muhlestein JB, Carlquist JF, et al. Serum uric acid independently predicts mortality in patients with significant, angiographically defined coronary disease. Am J Nephrol 2005;25(1):45-9.

4. Kotake H, Sawada Y, Hoshio A, et al. Relation between serum uric acid and angiographically defined coronary artery disease in postmenopausal women. J Med 1992;23 (6):409-15.
5. Johnson RJ, Feig DI, Herrera-Acosta J, et al. Resurrection of uric acid as a causal risk factor in essential hypertension. Hypertension 2005;45(1):18-20.

6. Tuomilehto J, Zimmet P, Wolf E, et al. Plasma uric acid level and its association with diabetes mellitus and some biologic parameters in a biracial population of Fiji. Am J Epidemiol 1988;127(2):321-36.

7. Yoo TW, Sung KC, Shin HS, et al. Relationship between serum uric acid concentration and insulin resistance and metabolic syndrome. Circ J 2005;69(8):928-33.

8. Athyros VG, Elisaf M, Papageorgiou AA, et al. Effect of statins versus untreated dyslipidemiaonserum uric acid levels in patients with coronary heart disease: a subgroup analysis of the GREekatorvastatin and coronary-heart-disease evaluation (Greace) study. Am J Kidney Dis 2004;43(4):589-99.

9. Jelic-Ivanovic Z, Memon L, Spasojevic-Kalimanovska V, et al. Independent association of high serum uric acid concentration with angiographically defined coronary artery disease. Tohoku J Exp Med 2007;211(4):369-77.

10. Persky VW, Dyer AR, Idris-Soven E, et al. Uric acid: a risk factor for coronary heart disease? Circulation 1979; 59(5):969-77.

11. Gur M, Yilmaz R, Demirbag R, et al. Relation of serum uric acid levels with the presence and severity of angiographic coronary artery disease. Angiology 2008; 59(2):166-71.

12. Palmer TM, Nordestgaard BG, Benn M, et al. Association of plasma uric acid with ischaemic heart disease and blood pressure: mendelian randomisation analysis of two large cohorts. BMJ 2013;347:f4262. doi:http://dx.doi.org/10.1136/bmj.f4262.

13. LiQin, Yang Z, Gu H, et al. Association between serum uric acidlevels and cardiovascular disease in middle-aged and elderly Chinese individuals. BMC Cardiovascular Disorders 2014;14:26. DOI:10.1186/1471-2261-14-26. 